\title{
SUPPORT OF ACTIVE AGEING THROUGH P2P LEARNING
}

\author{
BARBARA BASCHIERA \\ Department of Philosophy and Cultural Heritage, \\ University Ca' Foscari of Venice, Italy \\ E-mail address: barbara-baschiera@unive.it \\ WILLEM DE MEYER \\ PCVO Het Perspectief, Gent, Belgium \\ E-mail address: willemdemeyer@yahoo.com
}

\begin{abstract}
Personal development throughout the course of life is at the core of several important policy documents that have shaped European cooperation in economic, social and educational sciences over the last decade. The paradigm of Lifelong Learning implies learning at any age of life and underlines the importance of achieving continuous knowledge and self-care.

Pedagogy has started taking into account the age of older adults only in recent years.

The European project we are going to illustrate sought to test how well peer to peer learning can be useful to define new training and learning models for older adults.

The HiHtaST (Hand in Hand to a Social Tomorrow) project provides an example of peer to peer learning among older adults.

We provided training for adult learners to teach IT among other older adults as a means for social inclusion in five European countries. Each country had 20 learners / trainers who had other older students in turn.

Multiple choice questionnaires and focus groups were used to collect data.

The project was run in the theoretical framework of active ageing, considering the paradigm of Vygotsky's zone of proximal development and co-construction of knowledge.

The project results show that adults can acquire knowledge in peer to peer group situations with no drop-outs especially when learning real and practical tasks, which suggests that peer to peer learning works better than a frontal class in formal as well as non-formal or informal situations.
\end{abstract}

Key words: older adults, peer to peer learning, key competences 


\section{THE NEUROPHYSIOLOGICAL AND PSYCHOLOGICAL BASIS OF LIFELONG LEARNING}

It is believed that once the brain has fully developed it tends to decline and enters a degenerative process which is irreversible. Progress done by neuroscience, however, has shown that substantial changes in cortical areas occur at any age and that learning deeply transforms the structural functions of the brain.

Concepts such as neuroplasticity and neurogenesis have allowed us to understand that learning is possible not only in the younger generations but it can always occur and that it contributes to the increase of the neural regeneration, thus, it slows down the effects of old age (Guglieman, 2004; Luppi, 2008; Baschiera, 2012).

Moreover, the psychology of ageing (Cesa-Bianchi, 1987; Caretta, Petrini, Sandrin, 2002) has shed light on the need to go beyond the idea that ageing represents downfall or loss, and encourages a more positive image of this process.

Research has shown that ageing assumes more positive characteristics in the elderly who are still active, healthy, surrounded by intellectual stimuli, (Maderna, AveniCasucci, Baltes\&Castensen, 1996; Borowiak\&Kostka, 2004; Trabucchi, 2005; AndreaniDentici, 2006; Cesa Bianchi \&Cristini, 2009) and who spend their time in creative and recreational social activities -whether as a job or voluntary work or family activities.

Longitudinal psychological studies on the condition of the elderly (Zahodne, Glymour, Sparks et al., 2011) show that a high level of education and an active social life can be important in reducing cognitive decline (James, Wilson, Barnes et al., 2011).

The interconnection of research in psychology, neuroscience and education seems to offer new opportunities to investigate and experiment on the promotion of continuing education as a prerequisite to encourage personal well-being and social cohesion during the entire course of life.

Education for the elderly can represent a rewarding and efficient experience thanks to the creation of learning environments aimed at developing competences and the construction of knowledge, contexts in which strategies and activities use neuroplasticity principles to improve cognitive functions in the elderly.

\section{LIFELONG EDUCATION AND ACTIVE AGEING POLICIES}

According to the Lisbon strategy 2000 and to the strategic program Education $\mathcal{E}$ Training 2010, the European Member States have started to implement their policies for Lifelong Learning, being aware of the need to increase active participation of the elderly in order to achieve a knowledge- and Lifelong Learning- based economy. 
The European Commission's communication of $27^{\text {th }}$ September 2007 presents the Action Plan on Adult learning - It is always a good time to learn. Here the advantages deriving from continuing education -such as self-fulfillment and ageing in an improved physical and mental state- are explained in detail. Lifelong learning is recommended and supported also by the World Health Organization and it starts to have a crucial importance at a political level towards active ageing, to such extent that it has been promoted in formal, non-formal and informal contexts.

If the documents starting from 1999 had to be examined, some significant operational strategies dealing with the overcoming of ageing stereotypes could be followed. It is important to implement intergenerational and educational experiences to stimulate cognitive, meta-cognitive, relational, etc. dimensions of an elderly person.

Also during the the Second World Assembly on Ageing (UN, 2002, Resolution), the need to create a society for all ages, in which the elderly could have the right to be included in continuing education and be politically and economically active, was addressed. Active Ageing (WHO, 2002) focuses mainly on the rights of the elderly namely on their integration in the social environment. Along with the opening of the European Year for Active Ageing and Solidarity between Generations (2012), The European Commission points out some indispensable actions to promote Active ageing:

- creating sensible campaigns which value the potential in the elderly to develop their knowledge and their participation in the active society;

- promoting European projects for exchanges between older people who come from different countries, with the initiative to achieve continuing education;

- starting intergenerational educational projects to increase the opportunity of mutual learning and to challenge the danger of social isolation of older people.

There are various learning programmes and projects approved at both European and national level thanks to which older people are allowed more significant participation especially in informal contexts. However, some academics (Findsen \& Formosa, 2011) have discovered evidence that a low percentage of elderly people participated in the project in contrast with the younger generation; a very low percentage of foreign elderly people; a significant decline in participation over the age of seventy probably due to lack of information or physical / psychological obstacles.

These are isolated experiences and limited in time (Calza Bini, Lucciarini, 2011) issuing from the organisations and the partners involved.

In most cases, the European actions of Lifelong Learning revolve around a target of people over 50 who still work, purposely to guarantee economic productivity and in order to save retirement pensions. Today's politics seem to insist on it to show the sustainability of the increase of competent older people in the public system. 


\section{PEER TO PEER LEARNING: THEORIES AND STRATEGIES}

Most educational projects among peers with the aim of promoting active ageing, volunteering, learning in old age, active citizenship and solidarity, seem to give significance to the role of the learner's experience (Dewey, 1947) and to the empathy and the authenticity of relationships (Rogers, 1969). They also gather the models of learner-centered education (Cantor, 1946), discovery learning (Bruner, 1993) and the adult learning theory (Knowles, 1989).

These projects put the concepts of empowerment at the basis of the educational process.

Peer to peer education becomes, thus, as a social process that sustains a lot of different relationships: cooperation, collaboration, mutual interdependence in contexts of formal learning as well as non-formal and informal learning, according to four direct principles (Ripamonti, 2005):

- social skills education

- active citizenship education

- cultural education

- empowerment education.

HiHtaST (Hand in Hand to a Social Tomorrow) is a project that focuses on education as a social form, providing learning occasions with the desire of increasing the quantity and quality of the social relationships of older people in order to contrast the risks of social isolation and marginalization, improving the construction of the methods of communication and of meeting occasions. It is about providing the social context of old people's lives by connecting them through real pedagogical mediation.

With regards to the education of the active citizen, the reference is to the educational paths that develop competences in the making of social and cultural or care services (Risi, 2009). It is important, from an educational point of view, to give priority to those actions that support the development of social competences in a non- self-centered perspective.

The concept of education in terms of culture and update relates to projects that want to fulfill the desire of the elderly to enrich their knowledge and competences, coming closer to a discipline which was not cultivated previously.

The concept of empowerment refers to the implementation of the conditions and the processes allowing people to work to achieve their own goals and to overcome problematic situations by using their knowledge.

The main educational areas in which various projects are taking place are social and useful activities, cultural activities, technology courses.

The most common pedagogical aspect in educational projects among peers is that of scaffolding, which is strictly connected to the concept of proximal development zone (Vygotzskij, 1980), that is, "the distance between the actual developmental level as determined by independent problem solving and the level of potential development as determined through problem solving in collaboration with more capable peers". 
Educational experiences of peer mentoring and tutoring can be interpreted as "a virtual interconnection of proximal development zones in which many possibilities are brought to help, stimulate and orientate the learner in various ways", leaving space for autonomy and responsibility, in a climate of sharing and exchange (Calvani, 2000, pp. 80-81).

Spigner-Littles and Anderson (1999) underline that the oldest students learn better when the learning activity is structured in a way that:

it helps them to develop new competences;

it challenges their concepts and their point of view;

it contributes to reconsider the way they look at the world

it promotes the self-regulation of the learning process

Peer education also occurs through the occasions that learners have of being authors themselves and constructing their own knowledge. Furthermore, it occurs through the control and the monitoring of their own knowledge and the analysis of their experiences and competences.

Taking into consideration the six pillars of adult learning theory (Knowles, 1984):

- the need to know: before being involved in educational actions, adults want to know why they have to learn something;

- the concept of self: adults feel responsible for their decisions and for their lives and develop a deep need of being able of doing things themselves;

- the role of experience: adults enter a formative activity with their own experience;

- the willingness to learn: adults are willing to learn what they need to know in order to face various situations in life;

- the orientation about learning: adults learn from real life;

- motivation: adults are urged to learn from internal pressures;

it is understood that the educational activities among older people need to allow processes of cognitive methods and meta-cognitive criticism.

\section{TOWARDS A FRAMEWORK FOR PEER TO PEER LEARNING}

Questions about which kind of peer learning in the same age cohorts can be designed and which pedagogical paths can be structured -while respecting different time and learning method- to encourage the transition to a new culture of learning suiting the needs of older adults are open.

Bearing in mind that older people need to maintain solid social bonds and make new friends and acquaintances, the emotional dimension can be developed with the cognitive one.

Emotional and social factors play an important role in learning at any age in a way that it is important to create an environment which is full of connections when setting up a pedagogical project. 
It is therefore fundamental to maintain the centrality of learners and their experience as to educate through a teaching method which is based on the interest of the participants, their expertise and their life experience.

Educating according to constructive models reminds us that learning implies socialisation and the cultural acquisition of the meaning that the subject elaborates autonomously, in the light of the individual self.

Jonassen (1994) confirms that creating a constructive learning environment is much more complex than planning traditional pedagogical interventions, but also suggests some useful recommendations in the practice among peers:

- putting emphasis on the constructions of knowledge instead of its mere repetition;

- offering learning environments deriving from the real world;

- promoting reasoning and thinking;

- favouring the cooperative construction of knowledge through collaboration with others.

This entails an environment where the participants can exchange views and experiences following personal paces, times and styles. Such educational context offers stimuli and personal experiences which are adequate to the participants' personal interests.

Scaffolding is very strong and structured in every project (Calvani, 2000) and the trainer/facilitator seeks to:

- create an atmosphere of dialogue and of mutual acceptance;

- promote positive and constructive interpersonal relationships, so that the participants feel they are part of a community;

- give value to the learners' attendance;

- promote cognitive styles supporting multiple talents;

- construct shared meanings;

- stimulate meta-cognitive and self-reflexive processes.

Problem-solving, simulations, cooperative learning, mutual teaching are the most used strategies in peer education projects because they allow practical activities.

Such pedagogical approach conceives the construction of knowledge as an interactive process in which people learn from each other and not just from a narrator; it is in the nature of human culture to form a community where learning comes from mutual exchange (Bruner, 1997).

Today's knowledge society requires the individual should be the responsible protagonist of Lifelong learning. Constructive teaching is also applied in collaborative multimedia learning environments offered by information and communication technology.

Discussion forums, chat rooms and learners communities are environments in which older people can share and exchange their opinions and construct significant and motivating learning.

Workshop environments also promote peer to peer learning, as they are spaces in which different generations learn by doing surrounded by everyday things-namely theatre, creative writing, old professions, technology, kitchen, art. 
Connection and collaboration workshops to solve problems together, to create shared projects working together using the knowledge and ability developed within the group. These are spaces of reflexive action in which theory, techniques and practice, experience and reflection, emotion and rationality, generativity and creativity are pulled together.

Through the HiHtaST project we have sought to test how well the medium of peer-to-peer learning can spread solidarity as a means to increase the level of human capital for every generation.

\section{"HIHTAST" PROJECT}

Today's elderly also have to face very different and cognitively much more demanding situations and social scenarios than in the past. The proliferation of technology has created a so-called digital divide in which they are always at the disadvantaged end. Together with the development and the entrenchment of cultural models of productivity and efficiency, this has placed them in the unfortunate situation where they are often socially discriminated against, thereby affecting their level of participation in the economic and socio-cultural development. Active citizenship is connected to the ability to access information and those who are not educated in accessing modern media such as the Internet can be excluded from society (Mackay et al, 2001).

HiHtaST LLL project aimed at:

- empowering older adults in IT skills,

- creating a high quality learning environment,

- using IT to keep older people involved in society,

- organizing a peer to peer network for the mutual support of older people,

- adapting pedagogical models and learning material to the needs of the target group,

- establishing online contact among older people from different countries,

- exchanging good practices on IT training of older people,

- engaging older adults to learn new cultures,

- reducing isolation among certain vulnerable groups of people through peer-to-peer learning,

- $\quad$ creating specific lessons for older adults based on what they need in the IT society,

- creating a good climate to study in an informal way but with useful results in daily life,

- avoiding the drop-out of students through the help of classmates,

- $\quad$ sending older adults abroad teaching a foreign language in another European country.

The project is financed by the European Community and it focuses on IT skills for elderly people who want to learn how to use new technologies and how to teach/train their peers in the same field. 
The idea is to create a high quality learning environment for senior citizens.

The partners (coming from educational centers based in Belgium, Italy, United Kingdom, Portugal, Turkey), pointing out that learning needs to focus on the interests and motivation of older adults, experiences in education and the barriers faced in accessing education, investigated the needs of older adults who were going to participate in the project, concerning IT skills.

At the beginning of the project, a questionnaire was created to get a clear view on the learning needs of the target group. Their input were of major importance and were used for the development of the pedagogical material.

The partners shared good practices resulting in a pedagogical model, developing a training programme and learning material. They organised training sessions for older adults, established an online platform where they could meet, enabling them to become active online and to use the online technology. The older adults were provided with training which enabled them to operate a PC or a MAC, to use the internet and other relevant communication software such as Skype, Facebook, etc. A peer to peer network was established locally, nationally and internationally amongst older people and this network provided training and support to other elderly who needed it. This was a way for older adults in the EU to participate in social life, share experiences, connect with each other and learn new cultures, increasing collaboration and continuing education programs.

\section{METHOD}

During the project their feedback was considered and at the end they were asked to fill in a questionnaire to see if the project addressed their learning needs.

A multi-method approach was used for the analysis with a predominance of qualitative techniques. These sought to verify the achieved goals and the communication competences acquired (through observation, focus groups, self-analysis questionnaires, interviews).

Quantitative techniques were also used when analysing the responses of the evaluation questionnaires.

\section{FINDINGS}

The results of this monitoring suggested that:

The elderly strengthened relational competences among people from different countries, discovering new learning opportunities in a context that promoted solidarity.

Using ICT they could meet other European elderly groups, creating a network to learn about other European cultures and establishing new connections.

"What I liked most was the idea of meeting people from different countries who were in different areas and had different experiences. It was lovely chatting with somebody; I learnt quite a lot from their way of life and what they thought about different things. 
In this group there was a warm ...friendship ... It was great to learn so much about life from other people and their way of coping with things... I felt at home" (Italian participant).

These older adults found that learning in a group where they were all in the same situation about overcoming the fear of learning a new technology was of huge benefit to them.

A successful participation in educational and learning programmes can reinforce a sense of self-efficacy for older adults (Mehrotra, 2003). HiHtaST members, for example, found that being part of a group could help improve their selfconfidence, particularly in using technology: "Our age are not technology-minded. We didn't see the relevance of computers as easily as younger people, but as we learnt more, we began to see the relevance of computers to us" (Portuguese participant).

Older adults developed personal skills and competences such as: ability to participate actively in learning activities, to learn together with other people, to understand and accept different points of view, to adapt communication to situation, to express emotions and feelings (See figure 1).

They reported that two important aspects of participating in the HiHtaST project were acquiring new knowledge and trying new activities. Learners reported that keeping up with technological advances was important, especially to keep in touch with family and friends via email.

The need for practical experience was apparent in the course. Participants found that they had problems in remembering what they had learned, and mentioned that they needed constant repetition of material to memorize it.

A part of success of the classes with older adults were the schoolmates (also older adults) who had started ICT just some years earlier. The adult students liked to get help from somebody of almost the same age and that was an example that using ICT was still possible.

The classmates who helped in the class had a key role in the integration of all adults in the class group. Everybody understood that if the atmosphere was right it was a lot easier to learn. Different studies show that the environment where people study has a direct influence on their results and that peer support may be a factor in returning to education (King et al, 2002). This has implications for academic providers, in designing a curriculum that is diverse in teaching methodologies and settings and appropriate for adults of all ages.

One of the issues that is very common for most adults is that they are shy to ask their children and grandchildren basic ICT questions and fear negative reactions.

In this picture, peer learning appeared as an educational purpose and the background to design and structure interventions, activities, and contexts to support autonomous and active ageing and social cohesion.

Tutors noted at the beginning of the computer course that learners got often frustrated by their lack of knowledge or experience with technology, but with time and their scaffolding, this disappeared and they enjoyed the learning experience. 


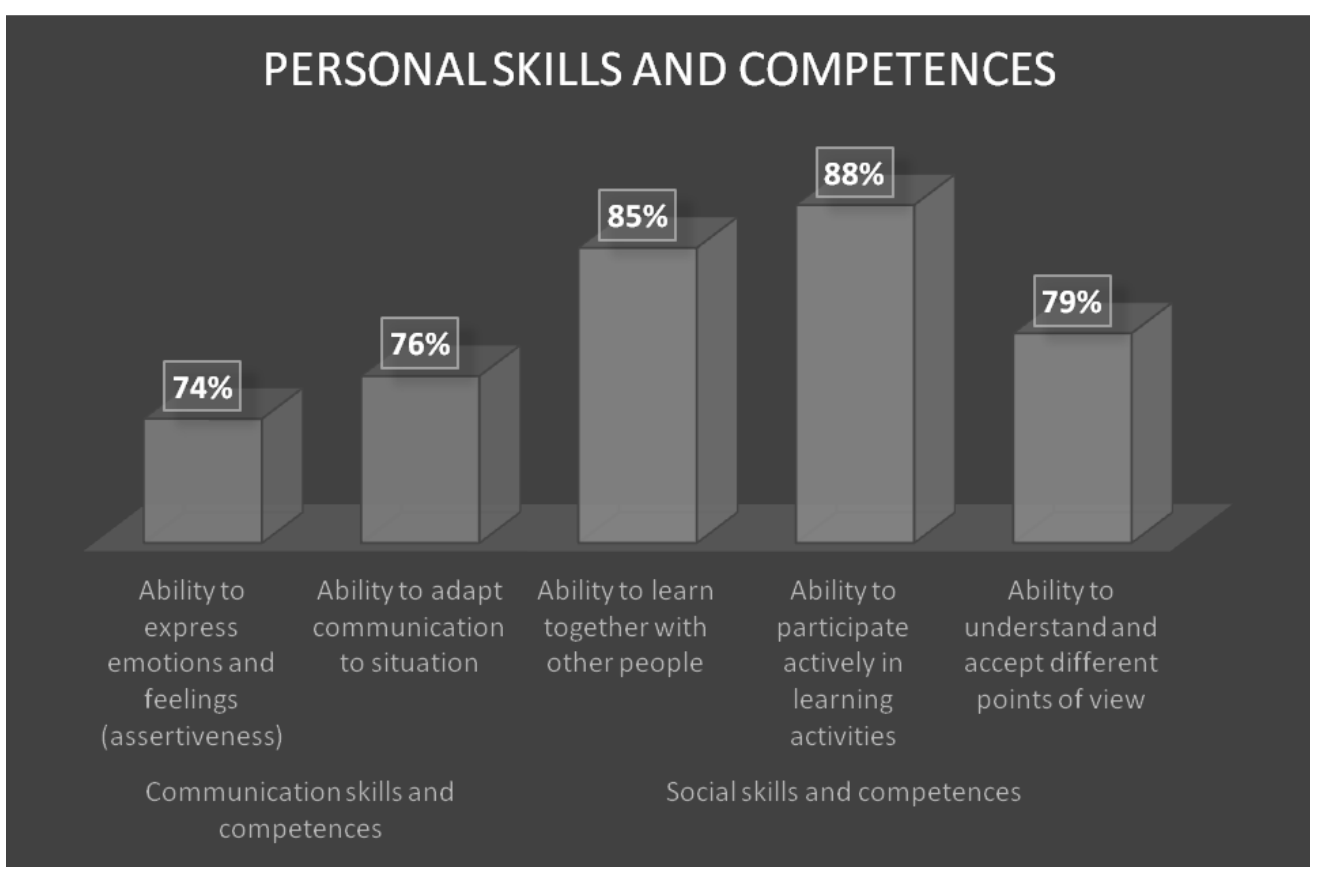

Fig. 1. Personal Skills and Competences Developed by the Elderly.

Source: Own chart.

"At first I felt full of doubts about even understanding the subject. Then I began to realize that I was learning more than I thought (Turkish participant)".

Some older learners had sensory problems that needed to be accounted for in the learning environment. One participant had problems viewing the screen, another mentioned that she had problems hearing. Both were supported by a facilitator and were happy in a one-to-one class situation while moving towards a certain degree of proficiency.

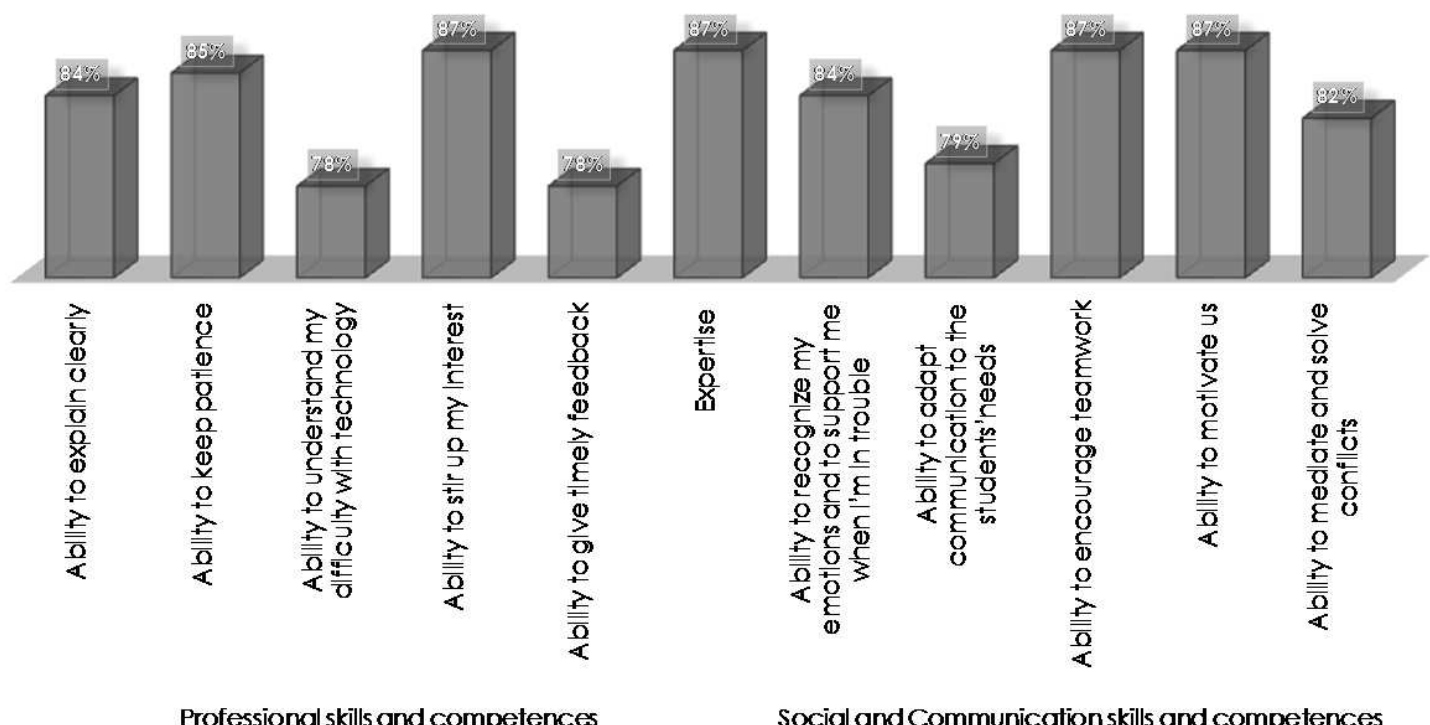

Fig. 2. Personal Skills and Competences Acknowledged by the Elderly. Source: Own chart. 
The elderly acknowledged those skills and competences in their trainers: the ability to increase their interest and expertise, to keep patience, to explain clearly, to understand their problems with technology and to give timely feedback. (See figure 2). They also underlined their social and communication skills and competences: the ability to encourage them, to motivate them, to mediate and solve conflicts, to adapt communication to their needs and empathy.

\section{CONCLUSION}

In a paper about this project, De Meyer (2014) underlines how seniors were motivated to follow the lesson in a good atmosphere without any drop-outs. That was because the elderly where supported by their peers in the class. That is a huge difference with normal classes where there are a lot of drop-outs because of lack of support. The teacher cannot help everybody.

The mix of classical teaching and classmates support to the elderly created the best results to keep them in the class. As the classmates were also older, the older adults accepted their help faster because they felt they were "equal" and they were already where all the students wanted to be: being self-reliant on the internet.

The project coordinator provided a platform for older people to share their life experiences and their variety of skills and talents with each other. It was a comfortable and safe environment that encouraged learning at an appropriate pace, using methods suiting the needs of the individuals involved. This is a useful model which could be adopted to suit a wide variety of groups of older people and the types of learning activities they wish to pursue.

This study brings suggestions from older learners themselves about their preferred styles of learning and how facilitators can meet their needs in the classroom. However, this research focused primarily on the facilitation of IT-based learning, without considering any gender issues or cultural issues. Future research on older adult learning should take these issues into account.

The elderly should not pursue simple instrumental learning, yet they should recombine their knowledge and skills in the light of the fickle life situations dealing with the complexity of today's life (Bauman, 2008).

\section{REFERENCES}

[1] Andreani Dentici, O. (2006). Ricordi molto lontani. La memoria a lungo termine nella vita quotidiana. Milano: Unicopli.

[2] Baltes, M. M., Carstensen, L. L. (1996). The process of successful ageing. Ageing and Society, $16,397-422$.

[3] Baschiera, B. (2012). Apprendimento intergenerazionale aperto. Studio di caso "Autobiografiamo?". FORMAZIONE \& INSEGNAMENTO, 3, 111-127.

[4] Bauman, Z. (2008). Vita liquida. Bari: Editori Laterza.

[5] Borowiak, E. \& Kostka, T. (2004). Predictors of quality of life in older people living at home and in institutions. Aging clinical and experimental research, 16 (3), 212-220. 
[6] Bruner, J. (1993). La mente a più dimensioni. Roma - Bari: Laterza.

[7] Bruner, J. (1997). La cultura dell'educazione. Milano: Nuovi orizzonti per la scuola, Feltrinelli.

[8] Calvani, A. (2000). Elementi di Didattica. Roma: Carocci.

[9] Calza Bini, P., Lucciarini, S. (2011). Barriere e opportunità all'implementazione di politiche di invecchiameto: una prospettiva comparata europea. Quaderni Europei sul nuovo Welfare, 16.

[10] Cantor, N. (1946). The dynamic of learning. Buffalo: Foster and Stewart.

[11] Caretta, F., Petrini, M., Sandrin, L. (2002). Educarsi all'anzianità, Torino: Paoline Editoriale Libri.

[12] Cesa-Bianchi, M. (1987). Psicologia dell'invecchiamento. Roma: La Nuova Italia Scientifica.

[13] Cesa-Bianchi, M., Cristini, C. (2009). Vecchio sarà lei! Muoversi, pensare, comunicare. Napoli: Guida.

[14] Dewey, J. D. (1947). Experience and education. New York: Macmillan.

[15] Findsen, B., Formosa, M. (2011). Lifelong Learning in Later Life: A Handbook on Older Adult Learning. Rotterdam: Sense Publishers.

[16] Guglielman, E. (2014). Il cervello plastico. Fondamenti neurofisiologici e strategie efficaci per l'apprendimento permanente. Contributo in atti di convegno Didamatica, Napoli, 7-9 maggio, 339-347.

[17] James, B. D., Wilson, R. S., Barnes, L. L., Bennet, D. A. (2011). Late-life social activity and cognitive decline in old age. J IntNeuropsycholSoc, 17 (6), 998-1005.

[18] Jonassen, D.H. (1994). Thinking technology, toward a constructivistic design model. Educational technology, XXXIV, 34-37.

[19] King, P., O' Driscoll S. \& Holden S. (2022). Gender and Learning. Dublin: National Association of Adult Education (AONTAS).

[20] Knowles, M. S. (1984). Andragogy in Action. San Francisco: Jossey-Bass.

[21] Knowles, M. S. (1989). The making of an adult educator: An autobiographical journey. San Francisco: Jossey-Bass.

[22] Luppi E. (2008). Pedagogia e terza età. Roma: Carocci.

[23] Maderna, A. M., Avena Casucci, M. A., Cesa Bianchi, M. (1973). “Aspetti psicologici dell'invecchiamento e della vecchaia", in F. M. Antonini, C. Fumagalli (eds), Gerontologia e Geriatria, Milano: Wassermann, I.

[24] Mahncke, H. W., Bronstone, A., Merzenich M. M. (2006). Brain Plasticity and Functional Losses in the Aged: Scientific Bases for a Novel Intervention. Progress in Brain Research, 157, 81-109.

[25] Mehrotra, C. M. (2003). In Defence of Educational Programs for Older Adults, Educational Gerontology, 29, 645-655.

[26] Ripamonti, E. (2005). Anziani e cittadinanza attiva. Imparare per sé, impegnarsi con gli altri. Milano: Edizioni Unicopoli.

[27] Risi, E. (2009). L'apprendimento contro l'invecchiamento. Le opportunità di formazione per gli anziani all'uso delle nuove tecnologie. Quaderni Europei sul nuovo Welfare, 12, 53-71.

[28] Rogers, C. R. (1969). Freedom to Learn. Columbus: OH: Merrill.

[29] Spigner-Littles, D. \& Anderson C. E.. (1999). Constructivism: a paradigm for older learners. Educational Gerontology, 25, 203-209.

[30] Trabucchi, M. (2005). Le fragilità. I vecchi, la città e la medicina, Bologna: Il Mulino.

[31] Vigotzskij, L. S. (1980). Il processo cognitivo. Torino: Paolo Boringhieri.

[32] Zahodne, L. B., Glymour, M. M., Sparks, C., Bontempo, D., Dixon, R. A., MacDonald, S. \& Manly J. J. (2011). Education does not slow cognitive decline with aging: 12-year evidence from the Victoria Longitudinal Study. Journal of the International Neuropsychological Society, 17 (6), 1039-1046.

[33] W.Willem De Meyer, Paper: Ontwerp van een Didactische methode voor Computeronderricht aan senioren, Belgium, 2014.

[34] Action Plan on Adult learning - It's never too late to learn. (2007). Retrieved from http:/ / eurlex.europa.eu/legal-content/EN/TXT/?uri=URISERV\%3Ac11102

[35] Active Ageing A Policy Framework (2002). Retrieved from http://apps.who.int/iris/ bitstream/10665/67215/1/WHO_NMH_NPH_02.8.pdf

[36] Communication from the Commission to the Council, the European Parliament, the Euro- 
pean Economic and Social Committee and the Committee of the Regions - Action Plan on Adult learning - It is always a good time to learn. (2007). Retrieved from http://eur-lex. europa.eu/legal-content/EN/TXT/?uri=CELEX:52007DC0558

[37] Detailed Work Programme on the Follow-up of the Objectives of Education and Training System in Europe. (2010). Retrieved from http://www.atee1.org/uploads/EUpolicies/ detailed_workprog_eandt2010.pdf

[38] Report of the Second World Assembly on Ageing (2002). Retrieved from https:/ / documentsdds-ny.un.org/doc/UNDOC/GEN/N02/397/51/PDF/N0239751.pdf?OpenElement

[39] Vygotsky, L. (1978). Interaction between learning and development. Retrieved from http://www. psy.cmu.edu/ siegler/vygotsky78.pdf

[40] Work programme on the follow-up of the objectives of education and training systems in Europe. (2002). Retrieved from http://europa.eu/legislation_summaries/education _training_youth/general_framework/c11086_en.htm 